\title{
Polycyclic aromatic hydrocarbons (PAHs) in surface soil from the Guan River Estuary in China: Contamination, source apportionment and health-risk assessment
}

\author{
Yingpeng $\mathrm{Yu}^{\mathrm{a}, *}$, Xiaoxiang Sun ${ }^{\mathrm{a}}$, Lili Zou ${ }^{\mathrm{a}}$, Huabing Zhang ${ }^{\mathrm{a}}$, Yuqing Liu ${ }^{\mathrm{a}}$, Min Liu ${ }^{\mathrm{b}}$ \\ a School of Urban and Planning, Yancheng Teachers University, Yancheng 224007 China \\ b School of Grographic Sciences, East China Normal University, Shanghai 200241 China \\ *Corresponding author, e-mail: pyy.lzu@163.com
}

Received 28 Jun 2019

Accepted 31 Dec 2019

\begin{abstract}
To analyse the distribution characteristics, potential sources and health risks of PAHs in the surface soil of the Guan River Estuary Industrial Area, 30 samples along the Guan River were collected. Sixteen types of PAHs were detected by gas chromatography-mass spectrometry (GC-MS). The results showed that the total content of the 16 PAHs ( $\Sigma 16 \mathrm{PAHs}$ ) ranged from $1212.8-12264.5 \mathrm{ng} / \mathrm{g}$, and the arithmetic mean and median were $3504.8 \mathrm{ng} / \mathrm{g}$ and $2396.5 \mathrm{ng} / \mathrm{g}$, respectively. The concentrations of 7 carcinogenic PAHs ( $\Sigma 7 \mathrm{carPAHs})$ ranged from $546.1-5742.3 \mathrm{ng} / \mathrm{g}$, accounting for $34-54 \%$ of the $\Sigma 16 \mathrm{PAHs}$. The pollution of the PAHs was intermediate compared with that of other industrial areas in China. Fluoranthene, pyrene and benzo[a] pyrene (BaP) are the main monomer PAHs. There was a weak positive correlation between the total organic carbon and the PAHs, and a negative correlation between the PAHs and the $\mathrm{pH}$ was found. The characteristic ratio and principal component analysis (PCA) show that the PAHs mainly come from combustion sources, especially the combustion process of coal and coke from industrial areas. The TEQBaP (toxic equivalency quantity relative to BaP) concentrations of 7 types of carcinogenic PAHs accounted for $99 \%$ of the $\Sigma 16 \mathrm{TEQBaP}$. According to the Canadian soil environmental quality standard, $87 \%$ of the sampling site's PAH pollution values exceeded the safety value, suggesting that there is a potential ecological risk in the Guan River Estuary industrial area.
\end{abstract}

KEYWORDS: Guan River Estuary, polycyclic aromatic hydrocarbons (PAHs), pollution level, health-risk assessment

\section{INTRODUCTION}

Polycyclic aromatic hydrocarbons (PAHs) are a typical persistent organic pollutant. Persistent polycyclic aromatic hydrocarbons (PAHs) are widely distributed in different environmental media. Because of their carcinogenicity, PAHs increased concern for risk to the environment and human health and have become the target pollutants of environmental studies [1]. PAHs mainly come from the incomplete combustion process of fossil fuels, biomass and organic matter [2]. In 1976, the United States Environmental Protection Agency (US EPA) listed 16 types of PAHs as priority pollutants [3]. Studies have found that soil is the main sink of PAHs and that $90 \%$ of $\mathrm{PAHs}$ in the environment are stored in surface soil in the UK $[4,5]$. PAHs generated by natural processes and human activities enter the environment and soil through a wet-dry deposition process. PAHs in soil pose a threat to human health through dusting, skin contact, and direct ingestion [6]. The pollution characteristics $[7,8]$, sources [9] and ecological risks [10,11] of PAHs in surface soil have been extensively studied in China. However, there is no report on related research on PAHs in the Guan River Industrial Area. The Guan River is the main river in northern Jiangsu, China. In the most recent ten years, the Guan River Industrial Area has developed rapidly, especially with the establishment of steelmaking and thermal power and petrochemical industry bases. More and more news on pollution in the estuary area have been reported. Researchers have carried out related studies, but the existing research focuses on nutrients and heavy metal pollutants with few research results [12]. However, there are no reports about the PAHs in the soil. Therefore, this study analysed the PAHs in the surface soil of the Guan River Industrial Area. The purpose is to investigate the $\mathrm{PAH}$ pollution characteristics to discuss the factors affecting PAH enrichment, to analyse the pollutant sources and to conduct an ecological risk assessment, all with 
a focus on providing basic data for managers to manage and control regional PAH pollution.

\section{MATERIALS AND METHODS}

\section{Sample collection}

In April 2017, surface soil samples were collected from an industrial area. The sampling points are shown in Fig. 1. The soil collection was based on a multi-point (5 points) mixed method. A stainlesssteel shovel was used to collect $0-10 \mathrm{~cm}$ of the surface soil, and 30 soil samples were collected and returned to the laboratory for freeze-drying and impurity removal prior to analysis.

\section{Extraction and purification}

The soil samples (5 g), copper powder and anhydrous sodium sulfate were added to a filter tank along with the internal standard substances (naphthalene- $\mathrm{d}_{8}$, acenaphthene- $\mathrm{d}_{10}$, phenanthrene$\mathrm{d}_{10}$, chrysene- $\mathrm{d}_{12}$ and perylene- $\mathrm{d}_{12}$ (Dr. Ehrenstorfer Company, Germany)), $120 \mathrm{ml}$ of acetone (HPLC grade, TEDIA Company, USA) and dichloromethane (HPLC grade, CNW, Germany) mixed solvents (volume ratio $\mathrm{V}: \mathrm{V}=1: 1$ ) in a Soxhlet extractor with a mean rate of 4 times/hour continuous reflux extraction for $20 \mathrm{~h}$. The extract was concentrated by rotary evaporation to approximately $1 \mathrm{ml}$, brought back up to a volume of $25 \mathrm{ml}$ with n-hexane, concentrated by rotary evaporation to approximately $1 \mathrm{ml}$ again and transferred to a $2 \mathrm{ml}$ brown vial. To reduce the influence of impurities on the PAH test, the concentrated liquid was transferred to a silica alumina column (volume fraction of silica and alumina was $2: 1$, wet filling) with hexane $(15 \mathrm{ml})$ and a mixed solvent of dichloromethane and hexane (70 $\mathrm{ml}$, volume fraction of $\mathrm{V}: \mathrm{V}=3: 7$ ) to elute the alkanes and aromatic hydrocarbons, respectively. The eluent containing the aromatic hydrocarbon component was concentrated to approximately $1 \mathrm{ml}$ for analysis.

\section{Instrumental analysis}

The concentration of the PAHs in the surface soil was tested by gas chromatography-mass spectrometry (GC-MS, Agilent, 7890A/5975C, USA). The gas chromatographic column was a DB-5 polysiloxane polymer column $(30 \mathrm{~m} \times 0.25 \mathrm{~mm} \times 0.25 \mu \mathrm{m})$. The column warming procedure was as follows. The column was held at $55^{\circ} \mathrm{C}$ for $2 \mathrm{~min}$, heated to $280^{\circ} \mathrm{C}$ at $20^{\circ} \mathrm{C} / \mathrm{min}$ and then heated to $310^{\circ} \mathrm{C}$ at $10^{\circ} \mathrm{C} / \mathrm{min}$ for $5 \mathrm{~min}$. The carrier gas was high-purity $\mathrm{He}$, and the velocity was $1 \mathrm{ml} / \mathrm{min}$. The scan mode was SIM
Table 1 Concentrations (ng/g) of the PAHs in the surface soil from the industrial area of the Guan River Estuary.

\begin{tabular}{lrrrrr}
\hline PAH & Min & Max & Mean & Median & SD \\
\hline NaP & 1.7 & 79.0 & 17.2 & 11.8 & 15.79 \\
Acy & 5.2 & 519.3 & 43.7 & 16.9 & 94.01 \\
Ace & 1.3 & 86.8 & 21.5 & 14.1 & 19.23 \\
Fluo & 6.9 & 129.9 & 36.8 & 23.7 & 35.44 \\
Phe & 56.2 & 915.6 & 295.7 & 217.7 & 235.52 \\
An & 13.1 & 250.1 & 68.8 & 47.4 & 68.60 \\
Fl & 176.7 & 2659.6 & 681.6 & 413.0 & 677.43 \\
Pyr & 189.2 & 2173.4 & 585.5 & 392.8 & 539.79 \\
B[a]A & 76.8 & 1457.6 & 290.4 & 204.9 & 279.19 \\
Chry & 102.0 & 1214.7 & 308.2 & 229.8 & 260.01 \\
B[b+k]F & 108.0 & 986.0 & 301.5 & 221.8 & 231.52 \\
B[a]P & 89.4 & 1737.6 & 336.6 & 234.8 & 326.03 \\
InP & 83.0 & 556.8 & 199.3 & 142.1 & 128.70 \\
D[ah]A & 21.9 & 287.4 & 74.4 & 50.7 & 66.66 \\
B[ghi]P & 93.2 & 770.2 & 243.6 & 170.3 & 174.46 \\
\hline$\Sigma(2+3)$ & 102.9 & 1359.8 & 483.8 & 343.6 & 363.72 \\
$\Sigma 4$ & 621.7 & 7237.2 & 1865.6 & 1225.9 & 1722.85 \\
$\Sigma(5+6)$ & 447.5 & 3831.7 & 1155.4 & 830.7 & 860.82 \\
$\Sigma 7$ carPAHs & 546.1 & 5742.3 & 1510.4 & 1108.7 & 1207.19 \\
\hline
\end{tabular}

mode. In this study, 16 United States Environmental Protection Agency (USEPA) priority controlled PAHs were detected and analysed: naphthalene (NaP), acenaphthylene (Acy), acenaphthene (Ace), fluorene (Fluo), phenanthrene (Phe), anthracene (An), fluoranthene (Fl), pyrene (Pyr), benzo[a] anthracene (BaA), chrysene (Chry), benzo[b] fluoranthene $(B[b] F)$, benzo[k] fluoranthene $(\mathrm{B}[\mathrm{k}] \mathrm{F}), \quad$ benzo[a] pyrene (BaP), indeno[1,2,3-cd] pyrene (InP), dibenz[a,h] anthracene (DahA) and benzo[ghi] perylene (BghiP).

\section{Quality control and quality assurance (QC/QA)}

A method blank, spiked blank and parallel experiment were used for quality assurance and quality control. The method blank experiment did not detect the target pollutants. The spike blank recovery range was between 74.7-106.3\%. The relative standard deviation of each parallel sample was controlled within $3 \%$. The detection limit was $0.07-0.12 \mathrm{ng} / \mathrm{g}$.

\section{RESULTS}

\section{Concentration characteristics}

The concentration distribution and total contents of the 16 monomer PAHs ( $\Sigma 16 \mathrm{PAHs}$ ) in the surface soil of the Guan River Estuary Industrial Area are shown in Table 1 . The concentrations of the $\Sigma 16$ PAHs 


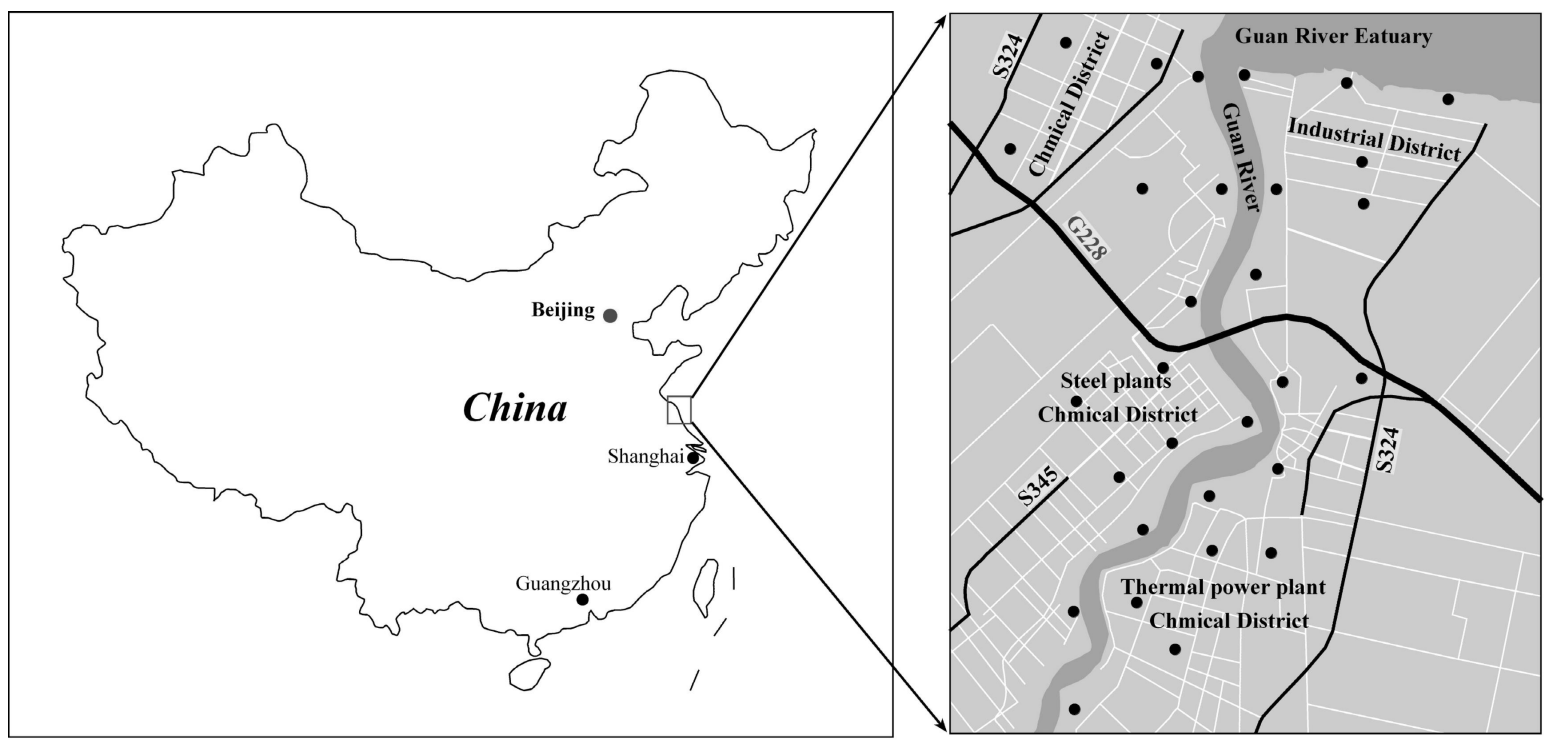

Fig. 1 Distribution map of the surface soil sampling points in the Guan River Estuary.

ranged from $1212.8-12264.5 \mathrm{ng} / \mathrm{g}$ with the arithmetic mean and median values of $3504.8 \mathrm{ng} / \mathrm{g}$ and $2396.5 \mathrm{ng} / \mathrm{g}$, respectively. Among them, the mean concentration of the $\Sigma 4$ ring PAHs was the highest (1865.6 ng/g), followed by the $\Sigma(5+6)$ ring PAHs (1155.4 ng/g), and the lowest concentration was the $\Sigma(2+3)$ ring PAHs $(483.8 \mathrm{ng} / \mathrm{g})$. The concentrations of the 7 carcinogenic PAHs ( $\Sigma 7 \mathrm{car}$ PAHs) listed by the US EPA ranged from $546.1-5742.3 \mathrm{ng} / \mathrm{g}$, had an arithmetic mean of $1510.4 \mathrm{ng} / \mathrm{g}$ and a median of $1108.7 \mathrm{ng} / \mathrm{g}$ and accounted for $34-54 \%$ of the $\Sigma 16$ PAHs. Maliszewska-Kordybach established the classification standard for PAH pollution in soil. Concentrations of $\Sigma 16 \mathrm{PAHs}<200 \mathrm{ng} / \mathrm{g}$ represent uncontaminated soil, from $200-600 \mathrm{ng} / \mathrm{g}$ represent slightly polluted soil, 600-1000 ng/g represent polluted soil and $>1000 \mathrm{ng} / \mathrm{g}$ represent serious pollution [13]. According to this standard, all sampling points in the Guan River Estuary Industrial Area were seriously polluted, and the soil pollution problems in the study area should be further researched by the relevant departments.

Previous studies have shown that the median value of the PAHs in the surface soil in China is $730 \mathrm{ng} / \mathrm{g}$ [9], which is much lower than that determined in this study. The possible reason for this result is that this study mainly focuses on the pollution of PAHs in industrial area so that the sampling points are close to the pollution sources. Therefore, this study objectively reflects the actual situation. Compared with other industrial areas in China, the concentration of the $\Sigma 16 \mathrm{PAHs}$ was higher than those

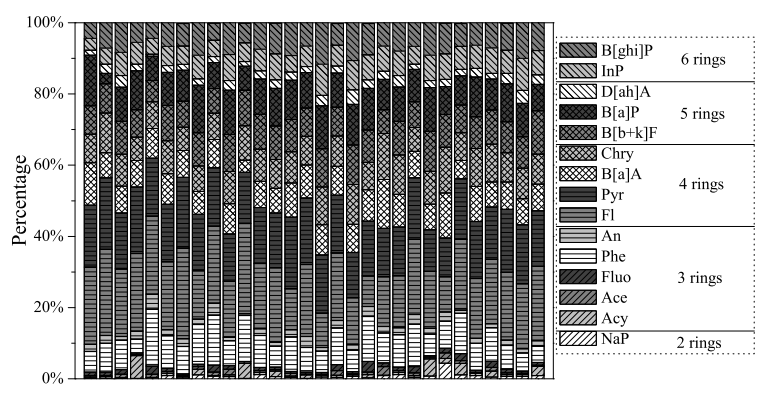

Fig. 2 PAH composition in surface soil from the Guan River Estuary.

determined for Nanjing (1060 ng/g) [14], Handan (398.9 ng/g) [15], Daqing (1839 ng/g) [16] and Shenyang (326.7 $\mathrm{ng} / \mathrm{g}$ ) [17], equivalent to that for Jinan $(2700 \mathrm{ng} / \mathrm{g})$ [18], and lower than that for Anshan (32100 ng/g) [19] and Dalian $(6440 \mathrm{ng} / \mathrm{g}$ ) [20]. Based on the PAH pollution in the surface soil in industrial areas, this study area has an intermediate pollution level.

\section{Composition characteristics}

The composition characteristics of the PAHs in the surface soil from the Guan River Industrial Area are shown in Fig. 2. The mean proportions of Fl, Pyr and $\mathrm{BaP}$ were the highest ( $\geqslant 10 \%)$; Fl accounted for up to $18 \%$, and Pyr and BaP accounted for $16 \%$ and $10 \%$, respectively. These were followed by Phe (9\%), Chry (9\%), B[b+k]F (9\%) and B[a]A (8\%). $\mathrm{Na}$, Acy, Ace and Fluo only represented $1 \%$.

Researchers have found that there is a high 


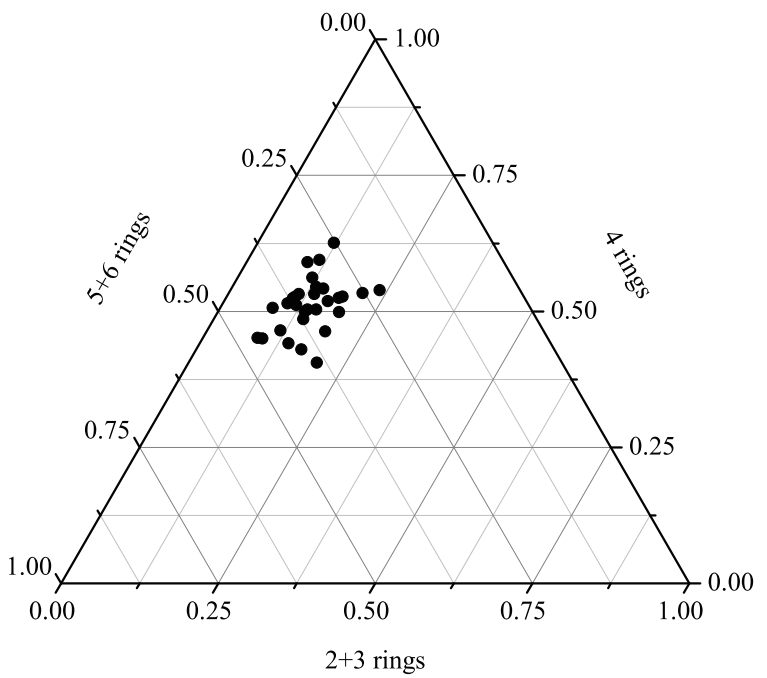

Fig. 3 PAH composition in surface soil from the Guan River Estuary.

proportion of Phe, Fluo and Pyr in Chinese surface soil [14]. However, there are differences in various regions of China, mainly due to different pollutant emissions. The PAHs can be divided into 2-3 rings (low rings), 4 rings (middle rings) and 5-6 rings (high rings) according to the different ring numbers. In this study, the higher contribution of Fl, Pyr, B[a]A and Chry led to the highest proportion of 4-ring PAHs, accounting for $51 \%$; this was followed by 5-ring and 6-ring PAHs, accounting for $21 \%$ and $13 \%$, respectively (Fig. 3 ). The proportion of 3 ring and 2-ring PAHs is lower, only $12 \%$ and $3 \%$, respectively [9]. This is similar to the studies in other parts of China. The low-ring PAHs in the atmosphere mainly exist in the gas phase and have a long-range migration ability. However, the highring PAHs mainly exist in the atmospheric particle phase and have a weak long-range migration ability [21,22]. Therefore, point-source pollutant emission is the main source of high-ring PAHs in soil.

\section{DISCUSSION}

\section{$\mathrm{pH}$ and TOC analyses}

The total organic carbon (TOC) can affect physicochemical processes such as adsorption/analysis of soil materials and biodegradation and is considered a major factor affecting the accumulation of PAHs in soil. The TOC did not significantly change in this study $(0.5-2.7 \%$, mean $1.6 \%)$. A correlation analysis showed a weak positive correlation between the TOC and $\Sigma 16$ PAHs $(n=30, r=0.319, p<0.01)$ (Fig. 4). Previous researchers reported that there
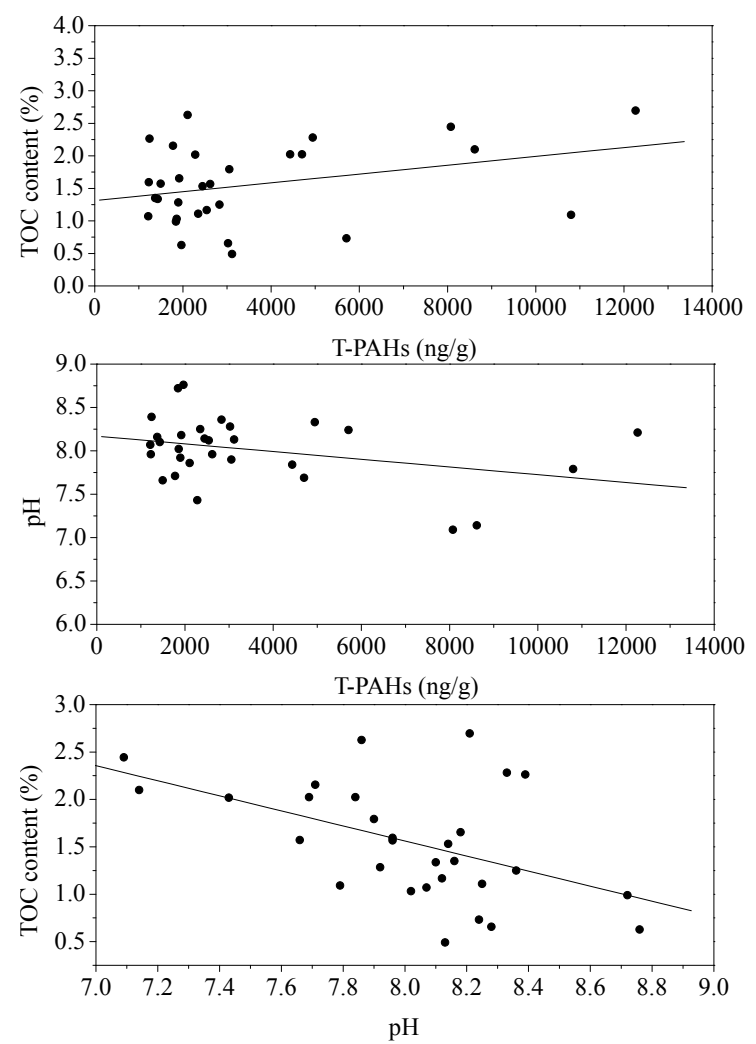

Fig. 4 Effect of the $\mathrm{pH}$ and TOC on the T-PAH concentrations in the surface soil. T-PAH $=\Sigma 16$ PAHs.

was a significant correlation between the TOC and the $\Sigma 16 \mathrm{PAHs}$ when the $\Sigma 16 \mathrm{PAH}$ concentration was above $2000 \mathrm{ng} / \mathrm{g}$ [23]. In this study, the mean concentration was $3504.8 \mathrm{ng} / \mathrm{g}$, which is much larger than $2000 \mathrm{ng} / \mathrm{g}$. However, the TOC and PAHs did not show a significant correlation. Studies have found that soil microorganisms play a role in the metabolism of organic matter. This reduces the impact of the TOC on the enrichment of the PAHs. This may be the main reason for the weak correlation between the TOC and PAHs. Changes in the soil $\mathrm{pH}$ change the TOC, affecting the PAH content changes [24]. We found a weak negative correlation between the $\mathrm{pH}$ and $\Sigma 16 \mathrm{PAHs}(n=30$, $r=-0.338, p<0.01$ ), and a moderate negative correlation between the TOC and $\mathrm{pH}(n=30, r=$ $-0.493, p<0.01$ ). The TOC content in more acidic soil is less because as the free organic matter in acidic soil decreases, the TOC solubility increases, making it easier for the TOC to drain. However, the organic-mineral complexes in soil are decomposed and destroyed under the action of the acid, becoming less complex particles, which are easily 
Table 2 Rotated component matrix.

\begin{tabular}{lrrr}
\hline \multirow{2}{*}{ PAH } & \multicolumn{3}{c}{ Component } \\
\cline { 2 - 4 } & \multicolumn{1}{c}{1} & \multicolumn{1}{c}{2} \\
\hline NaP & -0.032 & -0.039 & 0.973 \\
Acy & 0.157 & 0.903 & -0.053 \\
Ace & 0.718 & -0.271 & 0.293 \\
Fluo & 0.902 & -0.248 & -0.031 \\
Phe & 0.907 & -0.181 & 0.024 \\
An & 0.871 & 0.062 & -0.059 \\
Fl & 0.943 & 0.218 & -0.123 \\
Pyr & 0.949 & 0.243 & -0.095 \\
B[a]A & 0.916 & 0.132 & 0.023 \\
Chry & 0.953 & 0.127 & -0.017 \\
B[b+k]F & 0.949 & 0.251 & 0.016 \\
B[a]P & 0.773 & 0.293 & 0.073 \\
InP & 0.889 & 0.347 & 0.049 \\
D[ah]A & 0.856 & 0.209 & -0.034 \\
B[ghi]P & 0.907 & 0.205 & 0.043 \\
\hline \% Variance & 68.771 & 9.896 & 7.179 \\
\% Commutative & 68.771 & 78.667 & 85.846 \\
\hline
\end{tabular}

lost, resulting in the decrease in the organic matter content. The PAHs may be released simultaneously with the organic matter.

\section{Source apportionment}

The relative abundances of different molecular weight PAHs can be used to identify the source of the contaminants. Researchers have found that low molecular weight (LMW, $2+3$ rings) PAHs originate mainly from oil spills, while high molecular weight (HMW, $>4$ rings) PAHs are derived from fossil fuel combustion [24]. The LMW/HMW ratios were less than 1 (Fig. 5), and the highest ratio was only 0.313 , which suggested that the PAHs in the soil mainly come from the incomplete combustion of fossil fuels such as coal. Each PAH pollution source has its own unique composition and ratio. Therefore, some specific PAH isomers, such as $\mathrm{An} /(\mathrm{An}+\mathrm{Phe}), \mathrm{Fl} /(\mathrm{Fl}+\mathrm{Pyr}), \mathrm{BaA} /(\mathrm{BaA}+\mathrm{Chry})$ and $\operatorname{InP} /(\mathrm{InP}+\mathrm{BghiP})$, are often used to distinguish the source of PAHs in different environmental media [25]. As shown in Fig. 5, the An/(An+Phe) scatter points are mainly distributed in the region for the incomplete combustion emissions from wood, coke and coal and partly in the area of oil leakage and combustion. The $\mathrm{Fl} /(\mathrm{Fl}+\mathrm{Pyr})$ scatter points are mainly distributed in the areas of incomplete combustion emissions from gasoline, wood, coke and coal and partly in the region of diesel combustion and leakage. The scatter points for $\mathrm{BaA} /(\mathrm{BaA}+\mathrm{Chry})$ and $\mathrm{InP} /(\mathrm{InP}+\mathrm{BghiP})$ are mainly
Table 3 TEQ calculated as the TEF of the individual PAH relative to $\mathrm{BaP}(\mathrm{ng} / \mathrm{g})$.

\begin{tabular}{|c|c|c|c|c|c|}
\hline TEQ & TEF & Min & Max & Mean & SD \\
\hline $\mathrm{NaP}$ & 0.001 & ND & 0.08 & 0.02 & 0.016 \\
\hline Acy & 0.001 & ND & 0.52 & 0.04 & 0.092 \\
\hline Ace & 0.001 & ND & 0.09 & 0.02 & 0.019 \\
\hline Fluo & 0.001 & 0.01 & 0.13 & 0.04 & 0.035 \\
\hline Phe & 0.001 & 0.06 & 0.92 & 0.30 & 0.232 \\
\hline An & 0.01 & 0.15 & 2.50 & 0.69 & 0.675 \\
\hline $\mathrm{Fl}$ & 0.001 & 0.17 & 2.66 & 0.68 & 0.666 \\
\hline Pyr & 0.001 & 0.19 & 2.17 & 0.59 & 0.531 \\
\hline $\mathrm{B}[\mathrm{a}] \mathrm{A}$ & 0.1 & 7.68 & 145.76 & 29.04 & 27.450 \\
\hline Chry & 0.01 & 1.02 & 12.15 & 3.08 & 2.556 \\
\hline $\mathrm{B}[\mathrm{b}+\mathrm{k}] \mathrm{F}$ & 0.1 & 10.80 & 98.60 & 30.15 & 22.763 \\
\hline $\mathrm{B}[\mathrm{a}] \mathrm{P}$ & 1.0 & 89.41 & 1737.58 & 336.55 & 320.549 \\
\hline InP & 0.1 & 8.30 & 55.68 & 19.93 & 12.654 \\
\hline $\mathrm{D}[\mathrm{ah}] \mathrm{A}$ & 1.0 & 21.86 & 287.38 & 74.42 & 65.486 \\
\hline $\mathrm{B}[$ ghi $] \mathrm{P}$ & 0.01 & 0.93 & 7.70 & 2.44 & 1.715 \\
\hline \multicolumn{2}{|c|}{ TEQ of 7 PAHs } & 139.07 & 2337.15 & 493.17 & \\
\hline \multicolumn{2}{|c|}{ TEQ of 16 PAHs } & 140.58 & 2353.92 & 497.99 & \\
\hline
\end{tabular}

found in the coke, coal and diesel combustion regions. Overall, the PAHs mainly come from fossil fuel and petroleum combustion and partly from oil spills.

A principal component analysis (PCA) was used to further judge the sources of the PAHs. Three main factors were extracted by the SPSS software (Table 2). The 4-ring PAHs (Pyr, BaA, Chry and $\mathrm{B}[\mathrm{b}+\mathrm{k}] \mathrm{F})$ in factor 1 have a higher loading and represent the significant source of coal combustion as some findings were obtained in the literature [15, 26]. The high loading of Acy in factor 2 suggests an oil spill source [27]. Acy is considered a product of a petroleum source, including the leakage and spillage of petroleum during production and transport. The high loading of a 2-ring (NaP) $\mathrm{PAH}$ in factor 3 also represents an oil source [28].

\section{Risk assessment}

The mean TEQBaP concentration of the 16 types of PAHs ( $\Sigma 16 \mathrm{TEQBaP}$ ) in the soil was $498 \mathrm{ng} / \mathrm{g}$ (Table 3). The highest concentration was $2218.4 \mathrm{ng} / \mathrm{g}$, and the lowest was $156.9 \mathrm{ng} / \mathrm{g}$. The 7 types of carcinogenic PAHs ( $\Sigma 7 \mathrm{cTEQBaP}$ ) had concentrations that ranged from 156.1$2210.1 \mathrm{ng} / \mathrm{g}$ with a mean value of $495.6 \mathrm{ng} / \mathrm{g}$, which accounted for the $99 \%$ of $\Sigma 16$ TEQBaP. The results showed that the risk of toxicity was mainly from the 7 types of carcinogenic PAHs, especially 

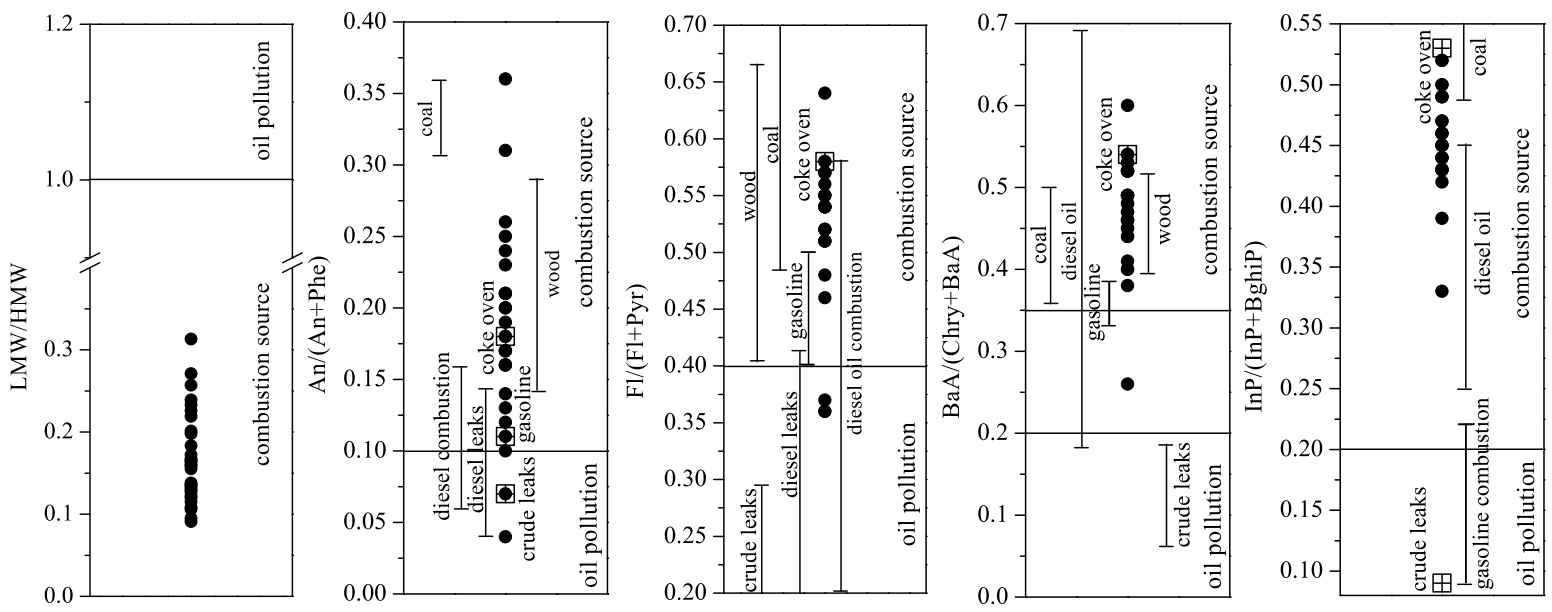

Fig. 5 Source apportionment of the characteristic ratios of the PAHs.

$\mathrm{BaP}(336.6 \mathrm{ng} / \mathrm{g}$ ) and D[ah]A (74.4 ng/g). The Canadian soil environmental quality standard stipulates a safety value for $\Sigma 16 \mathrm{TEQBaP}$ in soil of $600 \mathrm{ng} / \mathrm{g}$. The concentration of $\Sigma 16 \mathrm{TEQBaP}$ in soil around a coking plant was evaluated by multiplying the concentration by a coefficient of 3 [29]. In this study, the calculated $\Sigma 16 \mathrm{TEQBaP}$ concentration ranged from 470.6-6655.1 ng/g, and $87 \%$ of the sampling points exceeded the safety value, which indicated that there is a potential risk in the industrial area of the Guan River Estuary. Due to limited data, it is impossible to conduct a more comprehensive statistical analysis, and a risk assessment of the PAHs needs to be further studied.

\section{CONCLUSION}

The concentration range of the $\Sigma 16 \mathrm{PAHs}$ was from $1212.8-12264.5 \mathrm{ng} / \mathrm{g}$. The PAHs were mainly 4-ring PAHs, followed by 5- and 6-ring PAHs, while 2-3 ring PAHs represent the lowest content. $\mathrm{Fl}$, $\mathrm{Pyr}, \mathrm{BaP}$ are the main monomer PAHs; the Fl ratio was as high as $18 \%$, and the ratios of Pyr and $\mathrm{BaP}$ were $16 \%$ and $10 \%$, respectively. There is a weak positive correlation between the TOC and PAHs, and the biological community may reduce the effect of the TOC on the PAH enrichment. However, there was a moderate negative correlation between the $\mathrm{pH}$ and TOC. The results of the principal component analysis showed that the PAHs were mainly derived from coal combustion and partly from oil leakage. The concentration of the $\Sigma 7 \mathrm{CTEQBaP}$ accounts for 99\% of the $\Sigma 16 \mathrm{TEQBaP}$. BaP and D[ah]A are the highest carcinogenic risk monomer PAHs.

Acknowledgements: This work was supported by grants from the National Natural Science Foundation of China (Grant Nos. 41730646, 41501567, 41501003, 41771199, 41601594 and 41471060), the Natural Science Foundation of Jiangsu Province, China (Grant Nos. BK20160446, BK20160445 and BK20171277) and Jiangsu Province Environmental Monitoring Research Foundation Project (Grant No. 1713).

\section{REFERENCES}

1. Hamid N, Syed JH, Junaid M, Mahmood A, Li J, Zhang G, Malik RN (2018) Elucidating the urban levels, sources and health risks of polycyclic aromatic hydrocarbons (PAHs) in Pakistan: Implications for changing energy demand. Sci Total Environ 619-620, 165-175.

2. Bi C, Wang X, Jia J, Chen Z (2018) Spatial variation and sources of polycyclic aromatic hydrocarbons influenced by intensive land use in an urbanized river network of East China. Sci Total Environ 627, 671-680.

3. Ockenden WA, Breivik K, Meijer SN, Steinnes E, Sweetman AJ, Jones KC (2003) The global recycling of persistent organic pollutants is strongly retarded by soils. Environ Pollut 121, 75-80.

4. He FP, Zhang ZH, Wan YY, Lu S, Wang L, Bu QW (2009) Polycyclic aromatic hydrocarbons in soils of Beijing and Tianjin region: vertical distribution, correlation with TOC and transport mechanism. $J$ Environ Sci 21, 675-685.

5. Wild SR, Jones KC (1995) Polynuclear aromatic hydrocarbons in the United Kingdom environment: A preliminary source inventory and budget. Environ Pollut 88, 91-108.

6. Yang MM, Sun LN, Luo Q, Bing LF (2013) Health risk assessment of polycyclic aromatic hydrocarbons in soils of the Tiexi relocated old industrial area, Shenyang, China. Chin J Eco 32, 675-681.

7. Chen R, Lv J, Zhang W, Liu S, Feng J (2015) Polycyclic 
aromatic hydrocarbon(PAH) pollution in agricultural soil in Tianjin, China: a spatio-temporal comparison study. Environ Earth Sci 74, 2743-2748.

8. Cao H, Chao S, Qiao L, Jiang Y, Zeng X (2017) Urbanization-related changes in soil PAHs and potential health risks of emission sources in a township in Southern Jiangsu, China. Sci Total Environ 575, 692-700.

9. Zhang P, Chen Y (2017) Polycyclic aromatic hydrocarbons contamination in surface soil of China: A review. Sci Total Environ 605-606, 1011-1020.

10. Chen W, Wu X, Zhang H, Sun J, Liu W, Zhu L, Li X, Tsang DCW, et al (2017) Contamination characteristics and source apportion ment of methylated PAHs in agricultural soils from Yangtze River Delta, China. Environ Pollut 230, 927-935.

11. Yang W, Lang YH, Bai J, Li ZY (2015) Quantitative evaluation of carcinogenic and non-carcinogenic potential for PAHs in coastal wetland soils of China. Ecol Eng 74, 117-124.

12. He XR, Pang Y, Gao WJ, Deng HT, Chen BL, Chao SR, Song XJ (2015) Study on the vertical distribution and ecological risk assessment of PAHs in sediments of Guanhe Estuary. Environ Monitor China 3, 96-104.

13. Maliszewska-kordybach B, Smreczak B, Klimkowiczpawlas A (2009) Concentrations, sources, and spatial distribution of individual polycyclic aromatic hydrocarbons(PAHs) in agricultural soils in the Eastern part of the EU: Poland as a case study. Sci Total Environ 407, 3746-3753.

14. Wang $\mathrm{CH}$, Wu $\mathrm{SH}$, Zhou SL, Wang $\mathrm{H}$, Li BJ, Chen H, Yu YN, Shi YX (2015) Polycyclic aromatic hydrocarbons in soils from urban to rural areas in Nanjing: Concentration, source, spatial distribution, and potential human health risk. Sci Total Environ 527-528, 375-383.

15. Wu D, Wang YL, Liu WJ, Chen YC, Fu XF, Tao S, Liu WX (2016) Concentrations and component profiles PAHs in surface soils and wheat grains from the cornfields close to the steel smelting industry in Handan, Hebei Province. Environ Sci 37, 740-749.

16. Song NN, Feng JS, Yu Y, Li YX (2017) Comparison of characteristics and source apportionment of polycyclic aromatic hydrocarbons in different environmental media in the urban area of Daqing city. Environ Sci 38, 5272-5281.

17. Li JK, Song XY, Wei JB, Wang YY, Li YS, Zheng $\mathrm{XH}$ (2018) Pollution characteristics and source apportionment of polycyclic aromatic hydrocarbons in soils of Shenyang North New Area. Environ Sci 39,
379-388.

18. Yuan JP, Wang XL, Zhou JB, Chen XF, Zhao RS, Cheng CG (2015) Distribution, source and risk analysis of polycyclic aromatic hydrocarbons in top-soil from Jinan City. Environ Chem 1, 66-71.

19. Tian J, Zhu YY, Yang HB, Wu GP, Wei FS (2013) Investigation, assessment and source analysis of polycyclic aromatic hydrocarbons (PAHs) pollution in soil from a large iron and steel plant and its surrounding areas, in China. Environ Chem 32, 1002-1008.

20. Wang XT, Miao Y, Zhang Y, Li YC, Wu MH, Yu G (2013) Polycyclic aromatic hydrocarbons (PAHs) in urban soils of the megacity Shanghai: Occurrence, source apportionment and potential human health risk. Sci Total Environ 447, 80-89.

21. Kim KH, Jahan SA, Kabir E, Brown RJC (2013) A review of airborne polycyclic aromatic hydrocarbons (PAHs) and their human health effects. Environ Int 60, 71-80.

22. Wang Z, Yang P, Wang Y, Ma XD (2012) Urban fractionation of polycyclic aromatic hydrocarbons from Dalian soils. Environ Chem Lett 10, 183-187.

23. Tian WJ, Zhao FN, He XW, Li FS (2012) Effects of simulated acid rain on the release of polycyclic aromatic hydrocarbons from topsoils of an industrially contaminated site. Environ Chem 31, 497-503.

24. Yunker MB, Snowdon LR, Macdonald RW, Smith JN, Fowler MG, Skibo DN, Mclaughlin FA, Danyushevskaya AI, et al (1996) Polycyclic aromatic hydrocarbon composition and potential sources for sediment samples from the Beaufort and Barents Seas. Environ Sci Technol 30, 1310-1320.

25. Yunker MB, Macdonald RW, Goyette D, Patonb DW, Fowlerd BR, Sullivanc D, Boydc J (1999) Natural and anthropogenic inputs of hydrocarbons to the Strait of Georgia. Sci Total Environ 225, 181-209.

26. Qin L, Han J, He X, Liu Q (2014) The emission characteristic of PAHs during coal combustion in a fluidized bed combustor. Energ Source A 36, 212-221.

27. Harrison RM, Smith DJT, Luhana L (1996) Source apportionment of atmospheric polycyclic aromatic hydrocarbons collected from an urban location in Birmingham, UK. Environ Sci echnol 30, 825-832.

28. Simcik MF, Eisenreich SJ, Lioy PJ (1999) Source apportionment and source/sink relationships of PAHs in the coastal atmosphere of Chicago and Lake Michigan. Atmos Environ 33, 5071-5079.

29. CCME (2010) Polycyclic Aromatic Hydrocarbons, Canadian Soil Quality Guidelines for Protection of Environmental and Human Health. Canadian Council of Ministers of the Environment, Canada. 